\title{
Methods for the assembly and characterization of polyelectrolyte multilayers as microenvironments to modulate human mesenchymal stromal cell response
}

\author{
David A. Castilla-Casadiego ${ }^{1}$, Hemanta Timsina ${ }^{1+}$, Mahsa Haseli ${ }^{1+}$, Luis Pinzon-Herrera $^{1+}, \mathrm{Yu}-$ \\ Hsuan Chiao', S. Ranil Wickramasinghe ${ }^{1}$, and Jorge Almodovar ${ }^{1 *}$ \\ 'These authors contributed equally. \\ ${ }^{1}$ Ralph E. Martin Department of Chemical Engineering, University of Arkansas, 3202 Bell \\ Engineering Center, Fayetteville, AR 72701, USA. \\ *Corresponding author: Address correspondence to Jorge Almodovar, Ralph E. Martin \\ Department of Chemical Engineering, University of Arkansas, 3202 Bell Engineering Center, \\ Fayetteville, AR 72701, USA. Electronic mail: jlalmodo@uark.edu Phone: +1 479-575-3924, Fax: \\ +1 479-575-7926.
}

\section{Supporting information}

An example spreadsheet used to calculate amounts of different reagents required for layer-bylayer assembly. Procedure S1. Media preparation \& cell expansion. Procedure S2. Count cells. Procedure S3. Setting the parameters of the room and IR-VASE device. Procedure S4. Alignment of Samples. Procedure S5. Transmission test. Procedure S6. Determining the roughness of the coating. 
Table S1. An example spreadsheet used to calculate amounts of different reagents required for layer-by-layer assembly. Green cells represent user-entered values and blue cells contain

\section{calculations.}

\begin{tabular}{|c|c|c|c|}
\hline & $\mathrm{A}$ & $B$ & $\mathrm{C}$ \\
\hline 1 & Number of substrates & 2 & \\
\hline 2 & Number of bilayers & 6 & \\
\hline 3 & Volume of each wash & 10 & $\mathrm{~mL}$ \\
\hline \multicolumn{4}{|l|}{4} \\
\hline 5 & PEI volume required & $=\mathrm{B} 3 * \mathrm{~B} 1$ & $\mathrm{~mL}$ \\
\hline 6 & HEP volume required & $=\mathrm{B} 2 * \mathrm{~B} 3 * \mathrm{~B} 1$ & $\mathrm{~mL}$ \\
\hline 7 & COL volume required & $=\mathrm{B} 3 * \mathrm{~B} 2 * \mathrm{~B} 1$ & $\mathrm{~mL}$ \\
\hline 8 & Wash volume required & $=\mathrm{B} 1 * \mathrm{~B} 3+2 * \mathrm{~B} 2 * \mathrm{~B} 1 * \mathrm{~B} 3$ & $\mathrm{~mL}$ \\
\hline 9 & \multicolumn{3}{|l|}{ Round up to account for error: } \\
\hline 10 & 25 & $\mathrm{~mL}$ & PEI \\
\hline 11 & 130 & $\mathrm{~mL}$ & HEP \\
\hline 12 & 130 & $\mathrm{~mL}$ & $\mathrm{COL}$ \\
\hline 13 & 280 & $\mathrm{~mL}$ & Wash \\
\hline 14 & Buffer $\mathrm{pH} 4$ required & $=\mathrm{A} 12 * 2$ & $\mathrm{~mL}$ \\
\hline 15 & Buffer $\mathrm{pH} 5$ required & $=\mathrm{A} 13+\mathrm{A} 11+\mathrm{A} 10$ & $\mathrm{~mL}$ \\
\hline \multicolumn{4}{|l|}{16} \\
\hline 17 & \multicolumn{3}{|c|}{ Recipe: } \\
\hline \multicolumn{4}{|l|}{18} \\
\hline 19 & \multirow{3}{*}{$\mathrm{pH} 4$ solution } & $=3.1 / 1000 * \mathrm{~B} 14$ & mL Glacial Acetic Acid \\
\hline 20 & & $=1.27 / 1000 * B 14$ & g Sodium Acetate \\
\hline 21 & & $=\mathrm{B} 14$ & mL Ultrapure Water \\
\hline \multicolumn{4}{|l|}{22} \\
\hline 23 & \multirow{3}{*}{ pH 5 solution (wash included) } & $=1.3 / 1000 * \mathrm{~B} 15$ & $\mathrm{~mL}$ Glacial Acetic Acid \\
\hline 24 & & $=5.29 / 1000 *$ B15 & g Sodium Acetate \\
\hline 25 & & $=\mathrm{B} 15$ & mL Ultrapure Water \\
\hline \multicolumn{4}{|l|}{26} \\
\hline 27 & \multirow{2}{*}{$\mathrm{COL}$} & $=0.05 / 50 * \mathrm{~A} 12$ & g Collagen \\
\hline 28 & & $=\mathrm{B} 14$ & $\mathrm{~mL}$ pH4 buffer \\
\hline 29 & Note: Evaporate off until COL is & $=\mathrm{B} 28 / 2$ & $\mathrm{~mL}$ \\
\hline 30 & \multirow{2}{*}{ HEP } & $=0.05 / 50 * \mathrm{~A} 11$ & g Heparin \\
\hline 31 & & $=\mathrm{A} 11$ & $\mathrm{~mL}$ pH5 buffer \\
\hline \multicolumn{4}{|l|}{32} \\
\hline 33 & \multirow{2}{*}{ PEI } & $=0.05 / 50 * \mathrm{~A} 10$ & g PEI \\
\hline 34 & & $=\mathrm{A} 10$ & $\mathrm{~mL}$ pH 5 buffer \\
\hline & \multicolumn{3}{|c|}{ Note: Double the mass of PEl if it is $50 \%$ solution in water (which is typical) } \\
\hline
\end{tabular}


Procedure S1. Media preparation \& cell expansion (30 min).

Media preparation:

1. Obtain Alpha-minimum essential media ( $\alpha$-MEM) $(1 \times)$ from Gibco (supplemented with Lglutamine, ribonucleosides, and deoxyribonucleosides) and immediately thaw at $37^{\circ} \mathrm{C}$ water bath. Then transferring into a biosafety cabinet.

2. Add $20 \%$ fetal bovine serum, $1.2 \%$ penicillin-streptomycin, and $1.2 \%$ L-glutamine to the media.

Cell expansion:

1. Obtain hMSCs vial from nitrogen tank and immediately thaw at $37^{\circ} \mathrm{C}$ water bath. Place the vial inside the small beaker then put it inside the water bath and remove from the water bath once a small bit of ice is remaining (2-3 min).

2. Spray vial well with $70 \%$ ethanol before transferring into a biosafety cabinet.

3. Open the vial cap then transfer cells with $5 \mathrm{ml}$ pipette into a $15 \mathrm{~mL}$ centrifuge tube.

4. Slowly add $4 \mathrm{~mL}$ of culture media containing $20 \%$ fetal bovine serum, $1.2 \%$ penicillinstreptomycin, and $1.2 \%$ L-glutamine) into the cells.

5. Centrifuge the $15 \mathrm{ml}$ tube containing the cells at $200 \mathrm{xg}$ for $10 \mathrm{~min}$.

6. Place the vial inside the biosafety cabinet and carefully remove the supernatant that has accumulated at the bottom of the tube without disturbing the cell pellet.

7. Add $5 \mathrm{~mL}$ of culture media to cells and resuspend the cells with $5 \mathrm{~mL}$ pipet for 20 times.

8. Add $45 \mathrm{~mL}$ culture media to the cells.

9. Mix well and seed the cells into the T75 equally.

10. Transfer vessels into $37^{\circ} \mathrm{C}$ in a humidified incubator with $5 \% \mathrm{CO}_{2}$ and ensure that the surfaces are covered with media for 6 days.

Procedure S2. Count cells.

Count cells Manually:

- Prepare a sample with $50 \%$ cells in medium and 50\%Trypan Blue.

- Manually count the cells under the microscope using a hemacytometer (Neubauer's chambers).

- Determine the number of cells (cells $/ \mathrm{mL}$ ).

- Take several measurements and determine an average.

Countess $^{T M}$ II FL Automated Cell Counter:

- Prepare a sample with 50\% cells in medium and 50\%Trypan Blue. 
- Add10 $\mu \mathrm{L}$ of sample to Countess counting chamber $\mathrm{A}$ and10 $\mu \mathrm{L}$ to chamber $\mathrm{B}$ in a reusable or disposable slide.

- Wait 30 seconds to let the cells settle on the slide.

- Turn on the cell counter.

- Select and load a profile from the starting screen(e.g.,"Default") and click Load.

- Insert side $A$ of the slide in the slide port.

- Wait for the camera to focus.

- Select Count.

- Record the results or Click on Save to export to a USB device.

- Take out the slide.

- Reinsert side B of the slide and repeat the procedure. Take an average result.

Procedure S3. Setting the parameters of the room and IR-VASE device.

Verify-in the room that the following parameters meet the requirements stablished in Table S2:

Table S2. Optimal parameters of the room and IR-VASE device

\begin{tabular}{|l|c|}
\hline \multicolumn{1}{|c|}{ Parameter } & Accepted value or range \\
\hline Room Temperature & $65-75^{\circ} \mathrm{F}$ \\
\hline Room Humidity & $<60 \%$ \\
\hline Air Compressor Dryer Dew Point & Green area \\
\hline Air Compressor Pressure & $90-115 \mathrm{psi}$ \\
\hline Air Compressor Outlet Pressure & $\sim 75 \mathrm{psi}$ \\
\hline IR Purge Gas Generator Air Pressure Inlet & $\sim 70 \mathrm{psi}$ \\
\hline IR Purge Gas Generator Moisture Indicator & Green \\
\hline IR-VASE IR Box Dry Air Indicator & Blue \\
\hline IR-VASE IR Detetor Box Dry Air Indicator & Blue \\
\hline IR-VASE Dry Air Inlet Pressure & $\sim 29$ psi \\
\hline Air Compressor Manual Condensate & Drain \\
\hline Tripp-Lite Smart Online UPS Status & 2 or 20\% \\
\hline
\end{tabular}

Procedure S4. Alignment of Samples.

Open WVASE-IR software. Click the Align menu and then click on Load Sample. The equipment will automatically align at $90^{\circ}$. The Quad Detector Alignment window will appear. Use the tilt knobs to align $X$ and $Y$ until both are $<1$ and then click on Close. In the Translate Sample Stage 
Alignment window, rotate the $X$ and $Y$ knobs until a graph with a peak shows off; the higher the number, the better and then click on Close.

Procedure S5. Transmission test.

Open WVASE-IR software and perform the following procedure:

- Without Sample.

Click on Motors, Incidence Angle: $90^{\circ}$, and click on OK

Click on Motors, Incidence Angle: $0^{\circ}$, and click on OK

Click on System, Alignment, New Baseline, and click on Display Relative intensity

The Intensity will be approximately $1.0 \%$

- Place the sample.

Click on Motors, Incidence Angle: $90^{\circ}$, and click on OK

Click on Motors, Incidence Angle: $0^{\circ}$, and click on OK

Click on System, Alignment, New Baseline, and click on Display Relative intensity

The Intensity should be between $0 \%$ and $0.01 \%$.

Procedure S6. Determining the roughness of the coating (10 $\mathrm{min})$.

Since the procedure is very similar to the determination of thickness, it will be shown as a summary:

- Open WVASE32 software.

- In the Experimental Data window, do a right-click.

Click on File, click on Open exp. File and choose the file to analyze.

- $\quad$ Right-click $\rightarrow$ Range select (Experiment Window) $\rightarrow$ Wavelength (300-4000 1/cm) $\rightarrow$ ok

- Change Data type $\rightarrow$ Backside corrected type $\rightarrow$ ok

- Model $\rightarrow$ Add layer $\rightarrow$ IR Materials $\rightarrow$ si_ir $\rightarrow$ set $1 \mathrm{~nm}$ thickness $\rightarrow$ ok

- Right-click $\rightarrow$ add above si_ir $\rightarrow$ sio2_ntve_ir_g $\rightarrow$ Place a thickness of $2.583 \mathrm{~nm} \rightarrow$ ok

- Right-click $\rightarrow$ add above sio2_ntve_ir_g $\rightarrow$ default materials $\rightarrow$ select srough.may $\rightarrow$ enter

thickness previously measured $\rightarrow$ Check Fit $\rightarrow$ ok

- Generate data window $\rightarrow$ right click $\rightarrow$ Generate data

- $\quad$ Fit $\rightarrow$ Normal fit

- $\quad$ Fit $\rightarrow$ Pt. by Pt.

The sample roughness will appear in the Fit window. 